Eastern Illinois University

The Keep

Faculty Research and Creative Activity

Chemistry

January 2011

\title{
Enantiocontrolled solid-state photodimerizations via a chiral sulfonamidecinnamic acid
}

\author{
Kraig A. Wheeler \\ Eastern Illinois University, kawheeler@eiu.edu \\ Joshua D. Wiseman \\ Eastern Illinois University \\ Rebecca C. Grive \\ Eastern Illinois University
}

Follow this and additional works at: http://thekeep.eiu.edu/chemistry_fac

Part of the Organic Chemistry Commons

\section{Recommended Citation}

Wheeler, Kraig A.; Wiseman, Joshua D.; and Grive, Rebecca C., "Enantiocontrolled solid-state photodimerizations via a chiral sulfonamidecinnamic acid" (2011). Faculty Research and Creative Activity. 12.

http://thekeep.eiu.edu/chemistry_fac/12

This Article is brought to you for free and open access by the Chemistry at The Keep. It has been accepted for inclusion in Faculty Research and Creative Activity by an authorized administrator of The Keep. For more information, please contact tabruns@eiu.edu. 


\title{
Enantiocontrolled solid-state photodimerizations via a chiral sulfonamidecinnamic acid $\dagger$
}

\author{
Kraig A. Wheeler, * Joshua D. Wiseman and Rebecca C. Grove \\ Received 10th August 2010, Accepted 24th September 2010 \\ DOI: 10.1039/c0ce00516a
}

The supramolecular patterns of three polymorphs of a chiral sulfonamidecinnamic acid reveal components effectively organized into predetermined hydrogen-bonded dimers with favorable $<3.8 \AA$ olefin spacing for enantioselective single-crystal-to-single-crystal $[2+2]$ photodimerization reactions.

Chemical transformations in molecular crystals have experienced resurgence over the last decade due in part to greater accessibility of reactive phases. ${ }^{1}$ Prior to this time many prominent examples of both intra- ${ }^{2}$ and intermolecular ${ }^{3}$ programmed reactivity offered important impetus and practical insight into the structural features responsible for controlling solid-state reactions. From a structural standpoint, the main difference between these general classes of reactions is in their implementation: unimolecular strategies require a well-placed covalently bonded tether(s) between reacting centers whereas intermolecular processes necessitate exquisite supramolecular control. Significant attention to the first reaction type is not surprising, given that the relative orientation of the reacting centers is often more manageable within the confines of the single molecules.

The recent fundamental change in approach to exploring multicomponent solid-state reactivity originated from the systematic development of robust supramolecular synthons. ${ }^{1}$ This collective work, directed primarily at $[2+2]$ photocycloadditions, exploited the complementary cohesive properties of hetero- and homomeric functional group associations for organizing reactivity. Though such advances provide transferable methods for the spatial control of reactants, extending these strategies to include enantioselective reactions continues to pose significant challenge. ${ }^{4}$ How to integrate molecular/supramolecular chirality and chemical reactivity is at the center of this dilemma. This challenge has been extensively addressed for unimolecular processes via chiral induction, ${ }^{5}$ but enantiopure reaction outcomes involving two or more molecules remain a formidable obstacle due in part to insufficient structural tools for organizing reactive motifs. Incremental advances to this field will likely make use of next generation materials to extend the current margins

Department of Chemistry, Eastern Illinois University, Charleston, Illinois, USA. E-mail: kawheeler@eiu.edu; Fax: +1 01217581 6613; Tel: +1 01 2175813119

$\uparrow$ Electronic supplementary information (ESI) available: Hydrogen-bond tables for the five crystalline phases of $\mathbf{3}$. CCDC references numbers 787768 and 787772 . For ESI and crystallographic data in CIF or other electronic format see DOI: 10.1039/c0ce00516a of crystal engineering, developing innovative crystal reactions and other material properties of practical importance.

Our recent entry into multi-molecular photodimerization reactions integrated the structural preferences of sulfonamidecinnamic acids and the asymmetric organization of quasiracemic crystals. ${ }^{6}$ The design strategy behind these compounds complements current methods that assemble reactive components by promoting reaction atom economy and the construction of chiral crystalline environments for enantioselective transformations. Our crystallographic investigation of racemic and quasiracemic sulfonamidecinnamic acids 1 and 2 revealed structures with isostructural relationships (Scheme 1). Each molecule adopted key 'fish hook' topologies and formed supramolecular dimers. For racemate 1, these motifs consisted of pairs of heterochiral centrosymmetrically related molecules, while the analogous dimer in quasiracemate $\mathbf{2}$ showed the intended reduction in symmetry due to the distinct chemical properties of the dimer components. Both $\mathbf{1}$ and $\mathbf{2}$ effectively align adjacent $\mathrm{C}=\mathrm{C}$ bonds and underwent UV initiated single-crystal-to-single-crystal (SCSC) reactions. In the case of $\mathbf{1}$, the reaction gave a single racemic cyclobutane photoproduct, while quasiracemate $\mathbf{2}$ proceeded in a similar manner, but with an enantioselective outcome. The unique asymmetric organization of $\mathbf{2}$ produced a homochiral photodimerization product that represents a rare example of an engineered chiral bimolecular solid-state reaction.

Taking advantage of the potentially fertile crystal chemistry of sulfonamidecinnamic acid frameworks, this contribution extends our previous work by exploring a single-component homochiral
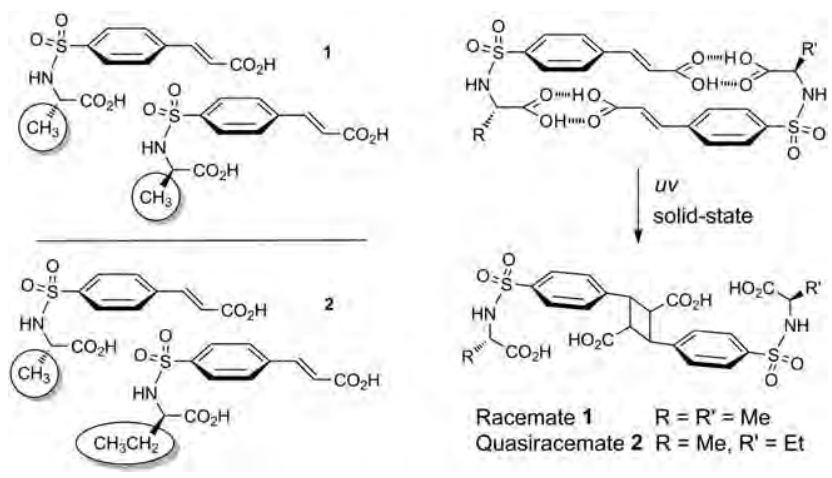

Scheme 1 Design strategy, supramolecular chemistry, and solid-state photodimerization of racemate $\mathbf{1}$ and quasiracemate $\mathbf{2}$. 
sulfonamidecinnamic acid. Alanine 3, an enantiopure precursor to racemate $\mathbf{1}$ and quasiracemate $\mathbf{2}$, provides an interesting opportunity to investigate solid-state reactivity and reliability of the hydrogenbonded dimer motif using a single-component enantiopure building block.

An important factor in the design of sulfonamidecinnamic acids $\mathbf{1}$ and 2 focused on exploiting the strong preference of racemates to crystallize with inversion relationships. ${ }^{7}$ While it is conceivable that this strategy could apply to other racemic and quasiracemic phases, the use of single-component homochiral compounds to form the desired inversion (or near inversion) related hydrogen-bonded dimers seemed less feasible. The consequence of this apparent structural incompatibility-i.e., component homochirality and the intended dimer motif centrosymmetry - to supramolecular assembly was unclear. A best-case scenario would involve use of complementary carboxyl $\cdots$ carboxyl interactions to assemble homodimers with near inversion related motifs. Because the design criteria of these systems included the appropriate framework and an assortment of hydrogen bonded donor $(\mathrm{NH}, \mathrm{OH}$, and $\mathrm{CH})$ and acceptor $(\mathrm{C}=\mathrm{O}$ and $\mathrm{S}=\mathrm{O})$ groups, other viable modes of molecular association are possible (e.g. catemeric patterns). Investigating this material (3) should further our current understanding of the structural parameters required to generate photoreactive hydrogen bonded dimers for this general compound class.

Chiral sulfonamide $\mathbf{3}$ was synthesized using a previously reported two-step process that incorporates chiral (alanine) and photoreactive (cinnamic acid) components. ${ }^{6}+$ Slow evaporation crystal growth studies of $\mathbf{3}$ from acetone (3-I) or 2-butanone (3-IIa and IIb) resulted in three distinct crystalline forms as determined by X-ray

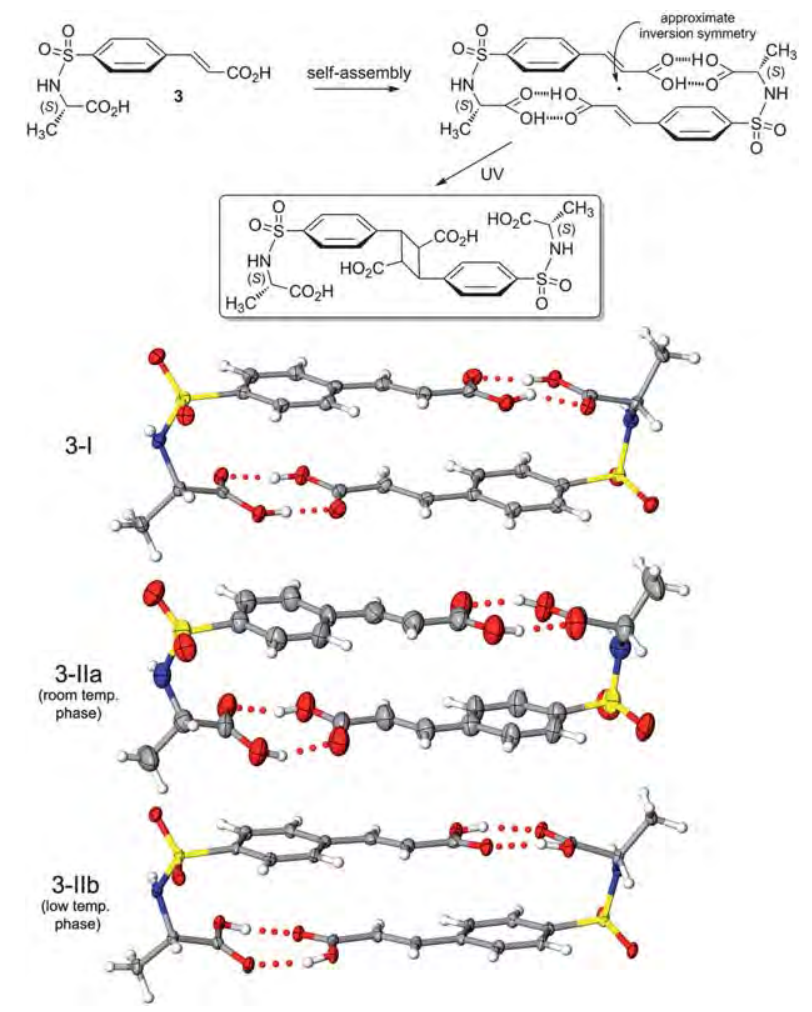

Fig. 1 Design strategy for the construction of photoreactive homodimers and asymmetric units ( $50 \%$ probability) of the three crystalline phases of 3 . crystallography. $\S$ Compound 3-IIa underwent a reversible temperature-dependent phase transformation to $\mathrm{IIb}$ with data collections performed on the same crystalline sample at 296 and $100 \mathrm{~K}$, respectively. The asymmetric units of 3-I, IIa, and IIb consist of a pair of homochiral symmetry-independent molecules of $\mathbf{3}\left(Z^{\prime}=2\right)$ that adopt the desired molecular 'fish hook' conformation (Fig. 1) and assemble to give nearly equivalent homomeric dimers via carboxyl head-to-head interactions. Interestingly, regardless of the diversity of these crystalline phases and imposed chirality of the components, the overall alignment of each homodimer of 3-I and II mimics inversion symmetry in triclinic space group $P 1$. The extent these motifs imitate true centrosymmetric relationships was investigated using the program Continuous Symmetry Measures (CSMs) recently developed by the Avnir group. ${ }^{8}$ The CSM method assesses the degree of symmetry by comparing the atomic spatial arrangement of a molecule or motif to that of its nearest achiral counterpart. Values range from 0 for motifs that possess the prescribed symmetry to 100 for highly distorted patterns. Applying this method to each homodimer motif of 3 gave CSM values [3-I (0.14), 3-IIa (0.16), and 3-IIb (0.15)] that indicated patterns with near inversion symmetry relationships similar to those observed for $\mathbf{1}$ and $\mathbf{2}$.

In addition to hydrogen-bonded dimers, inspection of the crystal packing of each phase reveals a variety of $\mathrm{N}-\mathrm{H} \cdots \mathrm{O}$ and $\mathrm{C}-\mathrm{H} \cdots \mathrm{O}$ interactions. As shown in Fig. 2a, homodimers of 3-I align by use of $\mathrm{N}-\mathrm{H} \cdots \mathrm{O}=\mathrm{C}$ and $\mathrm{C}-\mathrm{H} \cdots \mathrm{O}=\mathrm{S}$ contacts to give $2 \mathrm{D}$ patterns. Compounds 3-IIa and 3-IIb, related by a topotaxial phase change, differ by several subtle structural features. As can be seen in Fig. 3, slight variations in component and dimer conformations are also accompanied by a change in hydrogen-bond topologies. For 3-IIa, neighboring dimers assemble by use of $\mathrm{N}-\mathrm{H} \cdots \mathrm{O}=\mathrm{C}, \mathrm{N}-\mathrm{H} \cdots \mathrm{S}=\mathrm{C}$, and $\mathrm{C}-\mathrm{H} \cdots \mathrm{O}=\mathrm{S}$ hydrogen bonds, while the motifs of 3-IIb utilize $\mathrm{N}-\mathrm{H} \cdots \mathrm{O}=\mathrm{C}$ and $\mathrm{C}-\mathrm{H} \cdots \mathrm{O}=\mathrm{S}$ contacts for crystal cohesion. A prominent distinction of these structures is the apparent lack of $\mathrm{N}-$ $\mathrm{H} \cdots \mathrm{S}=\mathrm{C}$ contacts for 3 - $\mathrm{IIb}$ and the notable difference in alignment of molecular stacks along the $a$-axes of these structures.

Our previous crystallographic study of $\mathbf{1}$ and $\mathbf{2}$ revealed comparable translationally stacked hydrogen-bonded dimers with nearly

(a)

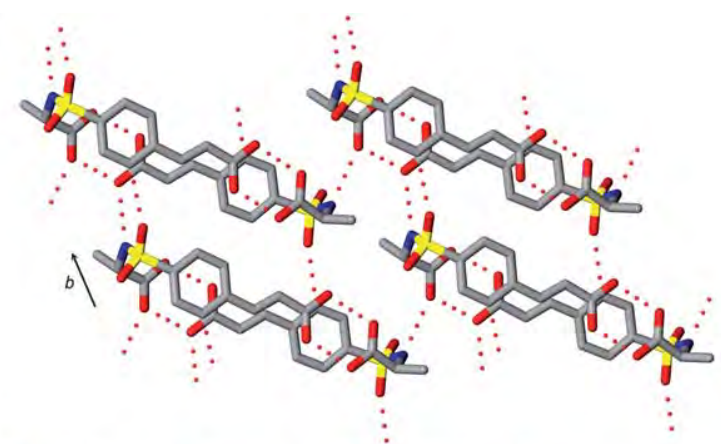

(b)

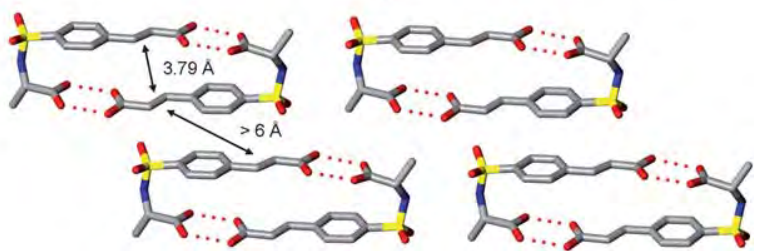

Fig. 2 Crystal packing of 3-I showing (a) hydrogen bond patterns and (b) homodimer alignment ( $\mathrm{H}$ atoms deleted for clarity). 
(a)
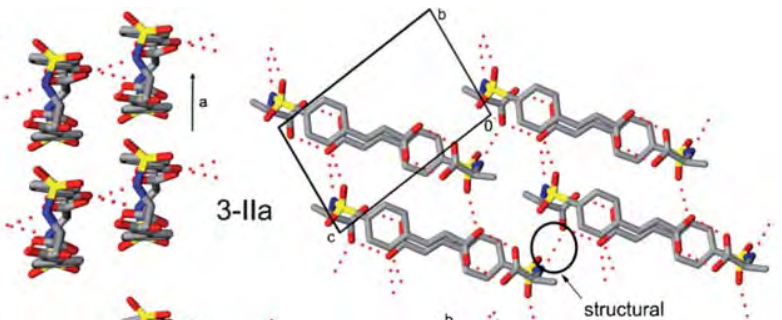

(b)
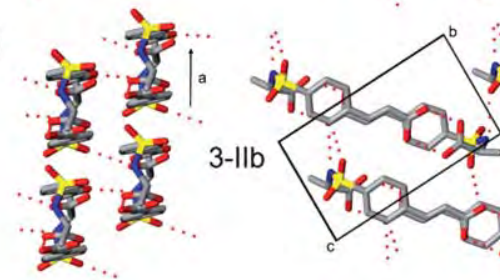

structural

Fig. 3 Crystal structure projections of the (a) room temperature and (b) low temperature phases of 3-II showing the variation in hydrogenbond patterns ( $\mathrm{H}$ atoms removed for clarity). (a)

(b)

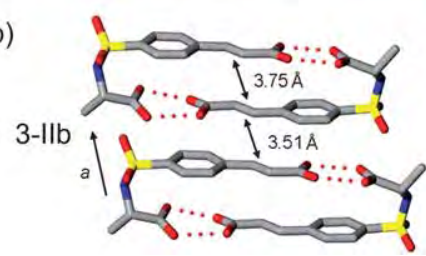

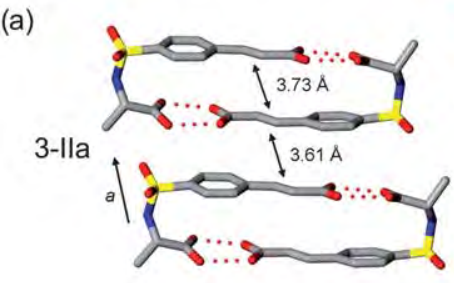
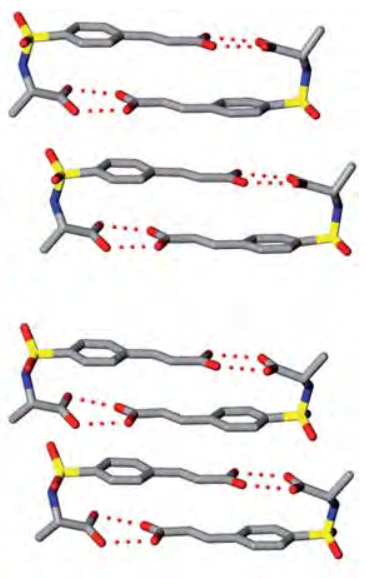

Fig. 4 Crystal structure projections of the (a) room temperature and (b) low temperature phases of 3-II showing alignment of homodimer motifs ( $\mathrm{H}$ atoms removed for clarity).

equal intra- and inter-dimer olefin distances $(<3.7 \AA)$. While each route satisfied the geometry criteria proposed by $\mathrm{Schmidt}^{9}$ for $[2+2]$ photodimerization reactions, tracking the reaction by X-ray diffraction showed product formation exclusively by the intra-dimer route. In contrast to the structural patterns reported for $\mathbf{1}$ and $\mathbf{2}$, multiple reaction pathways seem less likely for 3-I because of the proximity of the intra- and interdimer contacts (Fig. 2b). Contacts within the dimer for 3-I consist of $3.79 \AA$ olefin spacing whereas $>6 \AA$ for the next nearest neighbors. Inspection of Fig. 4 shows the two phases of 3-II organized into translational stacks of homodimers with favorable intra- and interdimer olefin contacts; the latter being slightly preferred based on distance criteria.

To investigate the solid-state reactivity of $\mathbf{3}$, samples were irradiated using a $200 \mathrm{~W} \mathrm{Xe}(\mathrm{Hg})$ arc lamp. $\uparrow \mathrm{A}$ UV tail-irradiated ${ }^{10}$ singlecrystal of 3-I remained intact thus providing an opportunity to assess reaction progress by single-crystal X-ray diffraction. The projections of the crystal structure of 3-I shown in Fig. 5 correspond to a $2 \mathrm{~h}$ exposure that resulted in quantitative conversion to the rctt cyclobutane photoproduct. Nominal motion of reactant molecules presumably drives the efficiency and SCSC behavior of this

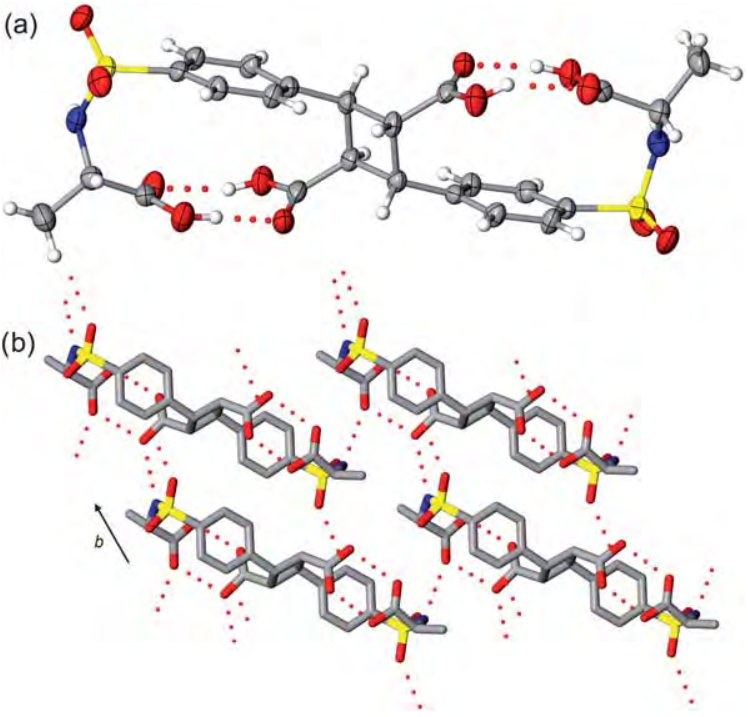

Fig. 5 UV irradiated 3-I showing (a) alignment of homodimer $(50 \%$ probability) and (b) hydrogen bond architecture ( $\mathrm{H}$ atoms deleted for clarity).

transformation and helps to retain the reactant hydrogen-bond framework during photodimerization (Fig. 2a and 5b). Because each supramolecular dimer consists of pairs of identical homochiral components with $S$ configuration, the absolute asymmetry of these reactant molecules translates to chiral reaction profiles and enantiopure photoproducts.

In a similar fashion, the sample corresponding to 3 -IIa and IIb was illuminated via the tail-irradiation technique. The low temperature phase 3-IIb lacked any observable reactivity after a $3 \mathrm{~h}$ exposure as indicated by the lack of electron density in the crystal structure $(100 \mathrm{~K})$ corresponding to product phase. Upon warming to $296 \mathrm{~K}$, the sample converted to 3-IIa and subsequent UV exposure for $0.5 \mathrm{~h}$ resulted in a severely fractured sample. X-Ray data collection using a segment of the original crystal revealed comparable photochemical behavior to 3-I. Although the reactant phase of 3-IIa suggested two possible reaction paths (i.e., intra- and interdimer paths), crystallographic assessment indicated quantitative conversion and product formation by an intradimer process. To our surprise, a comparison of the crystal structures of photoproduct phases 3-I and 3-IIa revealed nearly indistinguishable unit cell parameters and packing patterns. While the transformation of 3-I reactant to photoproduct involves only modest motion, photodimerization of 3-IIa requires extensive molecular reorganization. The substantial movement of 3 -IIa crystal components associated with photodimerization and a phase change likely follows a complex process resulting in partial crystal degradation.

In conclusion, we have successfully organized pairs of 'fish hook' shaped molecules into supramolecular dimers that persist despite the use of racemic (1), quasiracemic (2), and one-component homochiral (3) molecular scaffolds. This approach provides a powerful structural tool to align adjacent olefinic groups with $<3.8 \AA$ separation for UV initiated quantitative single-crystal-to-single-crystal transformations. Dimer motifs observed for 3-I and II exhibit reduced symmetry due to the $S$ absolute configuration of the components. The asymmetry of the building blocks translates to chiral supramolecular motifs that in turn encode the stereochemical outcome of the photodimerization 
process. This rational approach to programmed reactivity in molecular crystals circumvents the need for secondary molecules or metal atoms to align reacting centers and makes use of a new asymmetric auxiliary method to control the absolute asymmetry of photodimerizations.

\section{Acknowledgements}

We are grateful for support from the National Science Foundation (CHE-0957391 and CHE-0722547) and an EIU Council on Faculty Research Grant.

\section{Notes and references}

$\$$ Synthesis of compound 3. Preparation of $\mathbf{3}$ was carried out using a parallel procedure as described for sulfonamidecinnamic acids $\mathbf{1}$ and $2 .^{6}$ $41 \%$ overall yield. Mp $170{ }^{\circ} \mathrm{C}$ (dec.). Compound 3-I: ${ }^{1} \mathrm{H}-\mathrm{NMR}$ (acetone$\left.d_{6}, 400 \mathrm{MHz}, \mathrm{ppm}\right): \delta 7.91$ (d, $\left.J=16.3 \mathrm{~Hz}, 2 \mathrm{H}, \mathrm{Ar}-\mathrm{H}\right), 7.90(\mathrm{~d}, J=12.0$ $\mathrm{Hz}, 1 \mathrm{H}, \mathrm{N}-\mathrm{H}), 7.89$ (d, $J=16.3 \mathrm{~Hz}, 2 \mathrm{H}, \mathrm{Ar}-\mathrm{H}), 7.73(\mathrm{~d}, J=16.1 \mathrm{~Hz}, 1 \mathrm{H}$, $\left.\mathrm{C}_{\mathrm{sp} 2}-\mathrm{H}\right), 6.68\left(\mathrm{~d}, J=16.1 \mathrm{~Hz}, 1 \mathrm{H}, \mathrm{C}_{\mathrm{sp} 2}-\mathrm{H}\right), 4.05(\mathrm{dq}, J=7.2$ and 12.0 , $1 \mathrm{H}, \mathrm{CH}), 1.35\left(\mathrm{~d}, J=7.2,3 \mathrm{H}, \mathrm{CH}_{3}\right)$. Single crystals were obtained by sample dissolution in minimal amount of warm acetone (3-I) or 2-butanone (3-II) followed by slow evaporation at room temperature to yield colorless transparent plates or needles, respectively.

$\S$ Crystal structure determination. X-Ray diffraction data for 3-I and II were collected with a Bruker APEX-II equipped with a graphite-monochromator using $\mathrm{Cu} \mathrm{K} \alpha$ radiation $(\lambda=1.54178 \AA)$.

Crystal data for 3-I (reactant): $\mathrm{C}_{12} \mathrm{H}_{13} \mathrm{NO}_{6} \mathrm{~S}, M_{\mathrm{r}}=299.29$, triclinic space group $P 1, a=7.1020(2), b=8.0330(2), c=11.9154(3) \AA, \alpha=95.252(1)$, $\beta=104.650(1), \gamma=99.577(1)^{\circ}, V=642.12(3) \AA^{3}, Z=2, D_{\mathrm{c}}=1.548 \mathrm{~g}$ $\mathrm{cm}^{-3}, \mu=2.509 \mathrm{~mm}^{-1}, F_{000}=312, T=100(2) \mathrm{K}, 2 \theta_{\max }=68.23^{\circ}, 11522$ reflections collected (3910 unique), $R_{1}=0.0268$ and $\mathrm{w} R_{2}=0.0706[I>$ $2 \sigma(I)], R_{\text {int }}=0.0186, \mathrm{GOF}=1.07$, flack $=0.037(14)$.

Crystal data for 3-I (photodimerized): $\mathrm{C}_{24} \mathrm{H}_{26} \mathrm{~N}_{2} \mathrm{O}_{12} \mathrm{~S}_{2}, M_{\mathrm{r}}=598.59$, triclinic space group $P 1, a=7.0754(3), b=8.3189(3), c=11.0891(5) \AA$, $\alpha=94.832(2), \beta=102.101(3), \gamma=102.424(3)^{\circ}, V=617.51(4) \AA^{3}, Z=1$, $D_{\mathrm{c}}=1.610 \mathrm{~g} \mathrm{~cm}^{-3}, \mu=2.609 \mathrm{~mm}^{-1}, F_{000}=312, T=296(2) \mathrm{K}, 2 \theta_{\max }=$ $68.19^{\circ}, 12740$ reflections collected (3847 unique), $R_{1}=0.0301$ and $\mathrm{w} R_{2}=$ $0.0810[I>2 \sigma(I)] . R_{\mathrm{int}}=0.0238, \mathrm{GOF}=1.05$, flack $=0.035(16)$.

Crystal data for 3-IIa (reactant): $\mathrm{C}_{12} \mathrm{H}_{13} \mathrm{NO}_{6} \mathrm{~S}, M_{\mathrm{r}}=299.29$, triclinic space group $P 1, a=7.2536(2), b=8.0615(2), c=12.2344(2) \AA, \alpha=$ 79.453(1), $\beta=80.663(1), \gamma=71.819(1)^{\circ}, V=663.96(3) \mathrm{A}^{3}, Z=2, D_{\mathrm{c}}=$ $1.497 \mathrm{~g} \mathrm{~cm}^{-3}, \mu=2.426 \mathrm{~mm}^{-1}, F_{000}=312, T=296(2) \mathrm{K}, 2 \theta_{\max }=68.24^{\circ}$, 13758 reflections collected (4145 unique), $R_{1}=0.0365$ and w $R_{2}=0.0906$ $[I>2 \sigma(I)], R_{\text {int }}=0.0386, \mathrm{GOF}=1.03$, flack $=0.040(18)$.

Crystal data for 3-IIa (photodimerized): $\mathrm{C}_{24} \mathrm{H}_{26} \mathrm{~N}_{2} \mathrm{O}_{12} \mathrm{~S}_{2}, M_{\mathrm{r}}=598.59$, triclinic space group $P 1, a=7.0750(3), b=8.3144(4), c=11.1366(5) \AA$, $\alpha=94.937(3), \beta=102.315(3), \gamma=102.312(3)^{\circ}, V=619.34(5) \AA^{3}, Z=1$, $D_{\mathrm{c}}=1.605 \mathrm{~g} \mathrm{~cm}^{-3}, \mu=2.601 \mathrm{~mm}^{-1}, F_{000}=312, T=296(2) \mathrm{K}, 2 \theta_{\max }=$ $68.23^{\circ}, 12839$ reflections collected (3874 unique), $R_{1}=0.0543$ and $\mathrm{w} R_{2}=$ $0.1215[I>2 \sigma(I)] . R_{\text {int }}=0.0719, \mathrm{GOF}=1.03$, flack $=0.05(3)$.

Crystal data for 3-IIb: $\mathrm{C}_{12} \mathrm{H}_{13} \mathrm{NO}_{6} \mathrm{~S}, M_{\mathrm{r}}=299.29$, triclinic space group $P 1, a=7.2300(1), b=7.9762(1), c=12.5729(2) \AA, \alpha=87.318(1), \beta=$ $77.649(1), \gamma=63.576(1)^{\circ}, V=633.305(16) \AA^{3}, Z=2, D_{\mathrm{c}}=1.570 \mathrm{~g} \mathrm{~cm}^{-3}$, $\mu=2.544 \mathrm{~mm}^{-1}, F_{000}=312, T=100(2) \mathrm{K}, 2 \theta_{\max }=67.86^{\circ}, 12884$ reflections collected (3904 unique), $R_{1}=0.0321$ and $\mathrm{w} R_{2}=0.0836[I>$ $2 \sigma(I)] . R_{\mathrm{int}}=0.0346, \mathrm{GOF}=1.03$, flack $=0.021(14)$.

Empirical absorption corrections were applied using SADABS. ${ }^{11}$ Structures solved by direct methods and refined by full-matrix least-squares analysis on $F^{2}$ using X-SEED ${ }^{12}$ equipped with SHELXS. ${ }^{13}$ All nonhydrogen atoms were refined anisotropically by full-matrix least-squares on $F^{2}$ by the use of the SHELXL ${ }^{13}$ program. $\mathrm{H}$ atoms (for $\mathrm{OH}$ and $\mathrm{NH}$ ) were located in difference Fourier synthesis and refined isotropically with $\mathrm{O} / \mathrm{N}-\mathrm{H}$ distances restrained to $0.85(2) \AA$. The remaining $\mathrm{H}$ atoms were included in idealized geometric positions with $U_{\text {iso }}=1.2 U_{\text {eq }}$ of the atom to which they were attached ( $U_{\text {iso }}=1.5 U_{\text {eq }}$ for methyl groups)

ฯ Photochemical experiments. UV illumination studies for 3-I and IIa were carried out at room temperature $(296 \mathrm{~K})$ using a focused $200 \mathrm{~W}$
$\mathrm{Xe}(\mathrm{Hg})$ arc lamp (Newport Corp., 67005, 6292) equipped with a $360 \mathrm{~nm}$ optical edge filter (Newport Corp., CGA-360). For sample 3-IIb, the crystal was irrradiated with a flexible light guide while mounted on the diffractometer at $100 \mathrm{~K}$.

1 For reviews, see; Making Crystals by Design: Methods, Techniques and Applications, ed. D. Braga and F. Grepioni, Wiley-VCH Verlag GmbH, Weinheim, Germany, 2007, ch. 2.1-2.3, pp. 82-190; I. G. Georgiev and L. R. MacGillivray, Chem. Soc. Rev., 2007, 36, 1239; L. R. MacGillivray, G. S. Papaefstathiou, T. Frišcic, T. D. Hamilton, D.-K. Bucar, Q. Chu, D. B. Varshney and I. G. Georgiev, Acc. Chem. Res., 2008, 41, 280; L. R. MacGillivray, J. Org. Chem., 2008, 73, 3311; M. Nagarathinam, A. M. P. Peedikakkal and J. J. Vittal, Chem. Commun., 2008, 5277.

2 J. N. Gamlin, R. Jones, M. Leibovitch, B. Patrick, J. R. Scheffer and J. Trotter, Acc. Chem. Res., 1996, 29, 203; F. Toda, K. Tanaka, T. Tamashima and M. Kato, Angew. Chem., Int. Ed., 1998, 37, 2724; R. Sekiya, K. Kiyo-Oka, T. Imakubo and K. Kobayashi, $J$. Am. Chem. Soc., 2000, 122, 10282.

3 For reviews, see; V. Ramamurthy and K. Venkatesan, Chem. Rev., 1987, 87, 433; M. Hasegawa, Chem. Rev., 1983, 83, 507; I. Yoshikatsu, in Organic Molecular Photochemistry. Molecular and Supramolecular Photochemistry, ed. V. Ramamurthy and K. S. Schanze, Marcel Dekker, New York, USA, 1999, vol. 3, ch. 1, pp. 1-70; I. C. Paul and D. Y. Curtin, Acc. Chem. Res., 1973, 6, 217; F. Toda, Acc. Chem. Res., 1995, 28, 480; Solvent-Free Organic Synthesis, ed. K. Tanaka, Wiley-VCH GmbH \& Co., Weinheim, Germany, 2003.

4 M. Vaida, L. J. W. Shimon, J. van Mil, K. Ernst-Cabrera, L. Addadi, L. Leiserowitz and L. Lahav, J. Am. Chem. Soc., 1989, 111, 1029; M. Vaida, L. J. W. Himon, Y. Weisinger-Lewin, F. Frolow, H. Lahav, L. Leiserowotz and R. K. McMullan, Science, 1988, 241, 1475; F. Toda, in Organic Solid State Reactions. Topics in Current Chemistry, ed. F. Toda, Springer-Verlag, Berlin, Germany, 2005, vol. 254, ch. 1, pp. 1-40; F. Toda and K. Mori, Chem. Commun., 1989, 1245; F. Toda, in Topics in Stereochemistry, ed. S. E. Denmark and J. S. Siegel, John Wiley \& Sons, Hoboken, NJ, 2006, vol. 25, ch. 1, pp. 1-29; Y. Ito, Synthesis, 1998, 1; T. Lavy, Y. Sheynin, H. A. Sparkes, J. A. K. Howard and M. Kaftory, CrystEng Comm, 2008, 10, 734.

5 H. Koshima, D. Matsushige and M. Miyauchi, CrystEngComm, 2001, 33, 1; A. Natarajan, D. Ng, Z. Yang and M. A. Garcia-Garibay, Angew. Chem., Int. Ed., 2007, 46, 6485; T. Y. Fu, Z. Liu, G. Olovsson, J. R. Scheffer and J. Trotter, Acta Crystallogr., Sect. B: Struct. Sci., 1997, 53, 293; E. Y. Cheung, K. D. Harris, T. Kang, J. R. Scheffer and J. Trotter, J. Am. Chem. Soc., 2006, 128, 15554; M. Kaftory, F. Toda, K. Tanaka and M. Yagi, Mol. Cryst. Liq. Cryst., 1990, 186, 167.

6 R. C. Grove, S. H. Malehorn, M. E. Breen and K. A. Wheeler, Chem. Commun., 2010, 46, 7322.

7 M. Hendi, P. Hooter, V. Lynch, R. E. Davis and K. A. Wheeler, Cryst. Growth Des., 2004, 4, 95; B. Dalhus and C. H. Gorbitz, Acta Crystallogr., Sect. B: Struct. Sci., 2000, 56, 715.

8 M. Pinsky, D. Casanova, P. Alemany, S. Alvarez, D. Avnir, C. Dryzun, Z. Kizner and A. Sterkin, J. Comput. Chem., 2008, 29, 190; M. Pinsky, C. Dryzun, D. Casanova, P. Alemany and D. Avnir, J. Comput. Chem., 2008, 29, 2712.

9 M. D. Cohen and G. M. J. Schmidt, J. Chem. Soc., 1964, 1996; M. D. Cohen, G. M. J. Schmidt and F. I. Sonntag, J. Chem. Soc., 1964, 2000.

10 M. Kahn, V. Enkelmann and G. Brunklaus, Cryst. Growth Des., 2009, 9, 2354; I. Abdelmoty, V. Buchholz, L. Di, V. Enkelmann, G. Wegner and B. M. Foxman, Cryst. Growth Des., 2005, 5, 2210; J. B. Benedict and P. Coppens, J. Phys. Chem. A, 2009, 113, 3116.

11 G. M. Sheldrick, SADABS-Program for Area Detector Absorption Corrections, University of Göttingen, Göttingen, Germany, 2008.

12 L. J. Barbour, J. Supramol. Chem., 2001, 1, 189.

13 G. M. Sheldrick, Acta Crystallogr., Sect. A: Fundam. Crystallogr., 2008, 64, 112. 